\title{
O EDITOR DE REVISTA CIENTÍFICA: DESAFIOS DA PRÁTICA E DA FORMAÇÃO
}

\section{EL EDITOR DE REVISTA CIENTÍFICA: DESAFÍOS DE LA PRÁTICA Y FORMACIÓN}

\author{
Valdir Pereira Gomes - vagom2@yahoo.com.br \\ Mestre em Comunicação Científica e Tecnológica.
}

\begin{abstract}
Resumo
Este artigo oferece algumas reflexões a respeito das responsabilidades e funções do editor de revistas científicas frente à nova dinâmica editorial, impulsionada pelas atuais exigências de produtividade acadêmica e pela busca de melhores índices de desempenho dessas publicações. Discute a importância de sua formação e atualização profissional para atender as diretrizes e exigências de qualidade para esses veículos. Indaga acerca dos recursos e ferramentas que dispõe o editor para desempenhar uma atividade que requer constante processo de avaliação e atualização. Constata que desde o surgimento das publicações consideradas pioneiras, em meados do século XVII, até o atual e exponencial aumento de novos títulos, as revistas científicas impressas e digitais se reafirmam como meio mais rápido e economicamente viável para os cientistas fazerem circular e tornarem visíveis os resultados de seus estudos, criando um workflow nunca experimentado na história dessa comunicação especializada.
\end{abstract}

\section{Palavras-chave}

Comunicação científica. Revista científica. Formação do editor. Responsabilidade editorial. Qualidade editorial.

\section{DO FLORESCIMENTO À PROLIFERAÇÃO}

Longe de querer suscitar algum desconforto a respeito da analogia aqui empregada, uma vez que a palavra "proliferação", em seu uso comum, costuma remeter muito mais a uma reprodução descontrolada e leviana do que a um "crescer e se multiplicar" de forma natural, equilibrada e responsável, o meu intuito aqui, com este subtítulo introdutório, é oferecer subsídios para uma reflexão sobre as publicações científicas. Refletir, portanto, sobre a largada, o longo percurso até a contemporaneidade e as possibilidades do alcance de um futuro estável para as revistas científicas, no Brasil, 
e para o editor como mediador de todo o fluxo necessário à produção editorial desses veículos.

Tomo esta liberdade semântica com a intenção de, a partir de um ponto de vista da prática editorial e baseado em várias contribuições teóricas relevantes, ajudar no alargamento da compreensão sobre esse canal formal de comunicação da pesquisa científica, ao longo desses mais de três séculos de existência, desde o seu surgimento, em 1665, com o primeiro número do parisiense Journal dês Sçavans, seguido do inglês Philosophical Transactions of Royal Society of London. Até então, o processo de comunicação entre os cientistas, inicialmente organizados nos chamados "colégios invisíveis", dependia unicamente da correspondência pessoal de cartas e atas de reunião, meio comum para fazer circular e conhecer as novidades, descobertas e avanços do conhecimento entre seus pares:

\begin{abstract}
Estes grupos [os "colégios invisíveis"] - assim chamados para se diferenciarem dos colégios universitários oficiais (oficial university college) - serviram de base para a criação das sociedades e academias científicas. Seus membros participavam regularmente de encontros (alguns secretos), nos quais realizavam experimentos de pesquisa, avaliavam os resultados e discutiam sobre temas filosóficos e científicos. Os relatos e as conclusões desses encontros eram muitas vezes registrados, e as cópias, distribuídas como cartas ou atas a amigos que estavam desenvolvendo pesquisas análogas. Quando o número de participantes dos colégios se tornava muito grande, os membros se dispersavam ou se transformavam em organizações mais estruturadas e visíveis, como as academias e as sociedades científicas (STUMPF, 1996, p. 383)
\end{abstract}

Atribui-se ao pioneirismo francês, com o semanário Journal dês Sçavans lançado em 5 de janeiro de 1665, a preocupação de, além de atender às necessidades de publicação de assuntos do cotidiano social, oferecer catálogos completos de livros e novidades sobre as técnicas industriais e de divulgar

(...) experiências em física, química e anatomia que pudessem servir para explicar fenômenos naturais, descrever invenções de máquinas úteis ou curiosas e registrar dados meteorológicos; (...) informar os leitores sobre todos os acontecimentos dignos da curiosidade (LEMOS, 1968, p. 3).

Por conta do impacto que tais notícias sobre acontecimentos "dignos de curiosidade" começavam a causar no meio social, autoridades inquisitórias, naquele mesmo ano, conseguiram impedir a sua circulação, considerando herege o teor de seu conteúdo. Diante desses percalços, o editor decidiu interromper o semanário Journal dês Sçavans para não ter de editá-lo sob a constante vigilância da censura religiosa, embora sua periodicidade tenha sido retomada esparsamente entre 1666 e 1795, a partir de outros editores da época (FREITAS, 2005). 
Em maio de 1665, em Londres, surgiu a segunda revista dedicada a assuntos científicos: Philosophical Transactions. Diferente de seu congênere francês, o periódico da Royal Society of London era mensal ${ }^{1}$ e procurava concentrar suas edições na publicação de relatos de experimentos científicos, muitos deles desenvolvidos na própria Sociedade Real. Os temas mais abordados eram os que hoje conhecemos com sendo das Ciências Naturais. A revista evitava assuntos de caráter político ou religioso. A ideia era tentar manter um distanciamento seguro de temas polêmicos que rapidamente poderiam atrair os olhos onipresentes da Inquisição.

Naquele contexto histórico, isso não impediu, no entanto, o envolvimento dessa Sociedade em um episódio conhecido na Inglaterra como "anti-hobbismo". O filósofo inglês Thomas Hobbes (1588-1679), ao publicar a obra De corpore, ainda em 1665, entrou em um polêmico embate com alguns membros da Royal Society, por conta tanto das posturas ateístas que ele defendia, como pela sua posição teórica sobre a matemática. Este movimento contra o filósofo chegou a desencadear, em 1666, a queima de seus livros, estratégia muito usada na época para tentar silenciar posições contrárias e perigosas ao status quo político, religioso e, também, científico.

Com grande aceitação entre o público especializado, o periódico inglês chegou a ultrapassar a marca dos 1.200 exemplares, tiragem considerada satisfatória para a época. Hoje, há uma grande quantidade de revistas especializadas que circula com tiragem até inferior a esta (obviamente, guardando as devidas diferenças proporcionais de conteúdo e formato). A revista britânica foi também pioneira ao estabelecer o sistema de avaliação por pares (peer review), que passou a ser amplamente adotado pelas revistas, tornandose uma de suas características fundamentais ao longo dos séculos até a atualidade.

Embora com suas diferenças ainda não tão acentuadas quanto ao público-alvo e aos primeiros esboços de uma política editorial, o Journal dês Sçavans, pelas suas características editoriais, serviu de modelo para as revistas de divulgação científica que surgiriam depois e que viriam a despertar o interesse do público leigo, principalmente, pelas atividades desenvolvidas e assuntos científicos em geral. A Philosophical Transactions, por seu turno, serviu de modelo para a criação de revistas científicas, a maioria editada no seio das academias e sociedades da época, como meio de

\footnotetext{
${ }^{1}$ A Philosophical Transactions é a revista científica mais antiga ainda em circulação (a cada duas semanas), com Fator de Impacto em 2009 de 2.295. Sobre o termo "Fator de Impacto", ver nota 5.
} 
comunicação e circulação de informações e resultados de pesquisas entre o público especializado. Para se ter uma ideia da influência desses veículos pioneiros, somente no século XVIII, circularam por volta de mil periódicos, a grande maioria com uma curta vida editorial, algumas chegando a durar menos que três meses.

De acordo com Freitas (2005, p. 27), uma série de fatores colaborou para o florescimento e desenvolvimento do periódico científico até a modernidade, a partir do modelo europeu. Entre eles:

\begin{abstract}
O afrouxamento da censura religiosa sobre o conhecimento que se produzia, que em muitos pontos não condizia com o conhecimento veiculado pela Igreja, e, por conseguinte, diminuía o poder eclesiástico sobre os indivíduos; o afrouxamento do poder real sobre as agremiações científicas, que viam nelas o desenvolvimento de adversários políticos e também porque colocavam em questão muitas das verdades e decisões dos soberanos; o desenvolvimento das técnicas tipográficas e da comercialização de livros; e as grandes modificações práticas que proporcionaram o novo conhecimento, foram fundamentais para um novo formato de fazer e divulgar ciência no mundo moderno.
\end{abstract}

Dois séculos se passaram, desde o surgimento dos veículos precursores da comunicação científica na Europa, para que os primeiros periódicos dessa natureza começassem a ser publicados no Brasil. Stumpf (1996) salienta que a ascensão do periódico científico naquele continente e sua chegada ao Brasil só foi possível graças à Revolução Industrial, que possibilitou o aprimoramento das técnicas, inclusive dos mecanismos tipográficos, entre tantas outras inovações. A partir desse movimento iniciado no século XVIII, a ciência dinamizou seu processo de organização institucional e política, possibilitanto o desenvolvimento de seus sistemas de comunicação, entre eles, as experiências pioneiras de produção de jornais e revistas médicas durante o século XIX, que, segundo Rodrigues e Marinho (2009, p. 526), foram "os pilares da institucionalização da ciência no país".

Para Freitas (2006), os primeiros periódicos científicos brasileiros começaram a surgir no início do século XIX, sob a forma de "jornais literários", quase todos com vida editorial muito breve:

Os "jornais literários" traziam artigos técnico-científicos redigidos na linguagem própria da ciência, com várias observações sobre experimentos realizados, gráficos, tabelas e fórmulas. Traziam também vários artigos traduzidos de outros periódicos estrangeiros, comentários de outras obras e resumos de textos. (...). Muitas outras publicações, indexadas como "científicas", eram divulgadoras de breves notícias científicas. Outras ainda, indexadas como periódicos de "ciência política", eram publicações de cunho político, conforme se verificou, e não de "ciência". (p. 57 e 64-65) 
Não existe uma unanimidade entre os estudiosos desse campo da comunicação sobre qual foi, de fato, a primeira revista especializada a circular em meios científicos e acadêmicos no Brasil. No entanto, é comum a indicação de que a chegada das primeiras tipografias ao país, trazidas pela Corte portuguesa, foi o marco zero para as atividades editoriais como um todo. Obviamente, este não foi um processo simples, porque envolveu questões políticas e, ainda, religiosas, uma vez que muitas das atividades ligadas à tipografia dependiam da anuência de autoridades clericais e de suas relações com o poder político da época.

Não é o objetivo deste artigo, principalmente por questões limitadoras de espaço, resgatar e ampliar o panorama sobre os primórdios da revista científica no Brasil ou colaborar para uma elucidação sobre qual delas foi, de fato, a precursora nacional dos primeiros meios de comunicação científica. Vários autores (STUMPF, 1996; FREITAS, 2005, 2006; MARTINS, 2001, entre tantos outros) já se dedicaram exaustivamente ao estudo histórico do seu surgimento e desenvolvimento, com contribuições ao mesmo tempo fascinantes e contraditórias, como qualquer resgate dessa magnitude não poderia deixar de ser. Um fato, contudo, é oportuno destacar: em sua maioria, estes veículos também tiveram uma curta vida editorial, muitos não chegando a alcançar um ano de periodicidade e pouquíssimos atravessando as décadas seguintes à sua criação.

Analisando o constante surgimento e desaparecimento de revistas institucionais, que deram origem à criação de fundações e institutos de pesquisa e associações científicas no Brasil, Martins (2001, p. 327) observa o que chama de "curtos-circuitos" dessas publicações, cuja facilidade de surgimento decorria

(...) da impressão fácil e mão de obra pouco dispendiosa, despesas inicialmente garantidas tão-só com o pagamento de assinaturas. Com a alta do papel e a profissionalização do setor gráfico, apenas as associações puderam manter seus periódicos, valendo-se de anúncios pagos pelos laboratórios farmacêuticos.

Depois desse breve resgate histórico, chegamos ao século XX e agora avançamos por um novo milênio, com uma explosão de fontes documentais especializadas em todo o mundo (estima-se que mais de um milhão), em suportes impressos e eletrônicos (RODRIGUES; MARINHO, 2009). ${ }^{2}$

\footnotetext{
2 Para entender melhor as discussões sobre as mudanças de paradigmas advindos das novas tecnologias de informação e comunicação (TIC) e as relações históricas entre os suportes impressos e eletrônicos, consulte-se, entre outros, Chartier (1999), McLuhan (1972), Martin e Febvre (1992), Santaella (2003), Lévy (1993), Machado (1994).
} 
O número crescente de revistas científicas espalhadas pelo mundo, no entanto, não poderia ser considerado como fator negativo, como pareceu sugerir o subtítulo introdutório dessa reflexão. Do ponto de vista do conhecimento científico, quanto mais saberes se colocam em circulação, quanto mais resultados de estudos e pesquisas tornam-se acessíveis ao público especializado, tanto mais a comunidade científica e acadêmica $^{3}$ aproxima-se do seu ideal de contribuir para o avanço e a melhoria dos aspectos sociais, onde o conhecimento gerado por suas pesquisas pode e deve ser aplicado.

Entre o florescimento e a proliferação, o que de fato favorece o sucesso editorial de uma revista científica? Aquelas que nascem a partir de um planejamento editorial arrojado e bem alinhado às expectativas e exigências do campo de conhecimento ao qual se dirigem podem apresentar melhor potencial para se manterem em circulação. Todavia, esta prerrogativa poderia se aplicar a qualquer veículo que pretenda alcançar uma posição sólida no mercado editorial. Especulações à parte e certamente carentes de investigações mais detalhadas, o fato é que, mesmo hoje, não são incomuns os casos de revistas científicas que são lançadas e que, pouco a pouco, vão perdendo a sua periodicidade até deixarem de circular.

Não há editor que não tenha conhecido ou ouvido falar de alguma dessas "falências editoriais" ou mesmo transposição definitiva para plataformas eletrônicas, como estratégia para escapar da extinção. Várias razões poderiam ser apontadas como origem de problemas que concorrem para minar as "expectativas de vida" de uma revista científica, independente do suporte que utiliza, entre elas: 1) escassez de verbas (por desinteresse institucional e/ou por não apresentar os níveis de qualidade exigidos para obter recursos de agências financiadoras); 2) problemas de ordem operacional ou estrutural (como a falta de qualificação ou perfil profissional dos envolvidos em sua editoração); 3) dificuldades de captação de conteúdo (baixa demanda de colaboradores, muitas vezes gerada por questões de produtividade acadêmica, que pressionam pesquisadores pela busca de publicação em veículos com altos conceitos de avaliação); 4) mudanças políticas no interior da organização científica ou acadêmica em que foi criada.

\footnotetext{
${ }^{3}$ Sobre os fundamentos da Ciência \& Tecnologia e as diferenças nos padrões das atividades advindas dos modelos de ciência acadêmica e ciência aplicada, ver Bourdieu (1983), Kuhn (1978), Merton (1973), Vessuri (1995) e Schwartzman (2001, 2002).
} 
Com o intuito de refletir sobre alguns aspectos que envolvem os problemas operacionais e estruturais de uma revista científica, concentro as discussões seguintes em torno do trabalho do editor como um dos pilares que garantem o constante aprimoramento para a permanência desses veículos neste campo especializado da comunicação. Antes disso, porém, considero oportuno resgatar algumas informações ainda atuais sobre os indicadores de qualidade e crescimento da produção científica e, consequentemente, de seus meios formais de comunicação e difusão.

\section{UM PRODUTO EM CONSTANTE APRIMORAMENTO}

Em maio de 2009, a Thomson Reuters divulgou dados que comprovam um crescimento singular da produção científica brasileira de 2007 para 2008. De acordo com o balanço apresentado por este Instituto britânico, neste período a produção científica no Brasil cresceu $56 \%$, situação que, no ranking mundial de publicação de trabalhos em

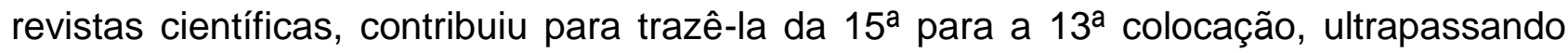
países como a Rússia e a Holanda. Com um total de 30 mil artigos, a produção científica brasileira passou a representar, naquele período, 2,12\% de toda a produção mundial de trabalhos publicados em revistas especializadas que integram a Thomson-ISI. ${ }^{4}$ Foram aceitos, em 2007, 19.436 artigos nacionais em revistas indexadas nesta base de dados. No ano seguinte, de acordo com dados do Instituto, este número saltou para 30.145 (MENEGHINI, 2009; GOIS, 2009).

No mesmo passo, o número de publicações nacionais indexadas no Institute for Scientific Information (ISI) quadruplicou de 2006 a 2008, quando alcançou a marca de 103 revistas. Entretanto, o panorama quase uma década atrás era outro e, digamos, bem desanimador: entre cerca de 16 mil publicações indexadas, apenas 17 eram brasileiras (TARGINO; GARCIA, 2000).

O que explica esta rápida mudança quantitativa na produção científica brasileira e o que isso tem representado para a dinâmica editorial das publicações especializadas? As opiniões e análises sobre esta nova realidade, embora explicitassem uma euforia pelo avanço nacional anunciado, não deixam de ser também controversas. $O$ motivo

\footnotetext{
${ }^{4}$ Fundado em 1958, por Eugene Garfield, o Institute for Scientific Information foi adquirido pela Thomson Reuters Corporation em 1992, quando passou a ser conhecido como Thomson-ISI. Além de fornecer diversos serviços como base de dados bibliográficos, contando com mais de 16 mil publicações indexadas, o Instituto publica, anualmente, o Journal Citation Reports, disponível na Web of Knowledge (http://isiknowledge.com), que oferece informações e análises estatísticas da literatura científica que integra a sua coleção. Com isso, é possível mapear e quantificar a dinâmica da atividade científica, tanto em termos dos meios de publicação quanto em termos dos agentes produtores de conhecimento científico.
} 
apresentado pelo ministro da Educação, Fernando Haddad (governo Lula), entre outras autoridades que participaram da Reunião Magna na Academia Brasileira de Ciências (Rio de Janeiro), em 5 de maio de 2009, de que este aumento se deveu, sobretudo, à política de fomento à pesquisa, não encontrou ressonância em todas as vozes presentes. Segundo Góis (2009), o argumento do ministro Haddad era de que contribuíram para esse resultado

(...) o aumento do número de mestres e doutores no Brasil, que saiu de 13,5 mil para 40,6 mil de 1996 a 2007, e o crescimento das bolsas concedidas pela CAPES (Coordenação de Aperfeiçoamento de Pessoal de Nível Superior), de 19 mil para 41 mil no mesmo período.

Meneghini (2009), por exemplo, aponta outra razão para esta mudança de status:

Muitas hipóteses foram levantadas, havendo até colegas que ironizavam ser um evento raro de desova de artigos científicos engavetados, como a desova de tartarugas marinhas. Por estar numa função que permite maior descortínio da produção científica, a explicação para o fato não me demorou. A base de dados Web of Science-ISI, utilizada nessa pesquisa, mostrou, sim, um aumento que o Brasil liderou: o de revistas científicas nacionais indexadas nessa base.

Mais revistas nacionais indexadas no ISI resultam, obviamente, em aumento da quantidade de produção científica brasileira nesta base de dados, sem, contudo, significar uma melhora qualitativa do desempenho internacional das revistas brasileiras, principalmente no que diz respeito ao Fator de Impacto. ${ }^{5}$

A dissonância reside no fato de que o governo federal vem investindo muito pouco em fomento a publicações científicas ( $R \$ 10$ milhões para cerca de 240 revistas, em 2008), em comparação com países como os Estados Unidos, que investem duzentas vezes mais do que isso e lideram o ranking, com 340 mil artigos publicados (MENEGHINI, 2009). Para serem aceitas em bases indexadoras internacionais, como o ISI, tais publicações passam por uma bateria de avaliações quando à sua qualidade formal e de conteúdo, além de aspectos relativos à periodicidade, circulação e pertinência à rede de conhecimento a que se propõe. Como alcançar um padrão de qualidade internacional com recursos limitados a cada ano?

\footnotetext{
${ }^{5}$ O termo Fator de Impacto (FI) foi desenvolvido em 1960 por Eugene Garfield e Irving Sher, com o objetivo de selecionar revistas para o Science Citation Index (SCl). Este índice é calculado a partir de duas informações básicas: a) o número de artigos publicados em dois anos consecutivos anteriores e b) o número de citações destes artigos no ano corrente (GARFIELD, 1955). Em seguida, divide-se o número de citações obtidas pelo total de artigos publicados. 0 resultado desta equação aparentemente simples oferece parâmetros estatísticos que ajudam a avaliar a importância e relevância relativas de um periódico e, desde a sua criação, tem alcançado grande aceitação na comunidade científica internacional, embora represente apenas um dos vários mecanismos por ela utilizados para estimar os níveis de qualidade, alcance e visibilidade dos trabalhos publicados e das revistas especializadas, em comparação com outras publicações do mesmo campo científico disponíveis em base de dados dessa natureza. Ainda sobre o Fator de Impacto, ver Garfield (1999), em uma revisão mais recente, e Smith (2006), que apresenta uma abordagem crítica desse fator estatístico.
} 
Estes dados parecem apontar para uma dinâmica paradoxal, uma vez que se percebe um avanço significativo, embora ainda não o ideal, na qualidade editorial das publicações nacionais, ao mesmo tempo em que se observa uma escassez de fomento que assombra as instituições responsáveis pela produção destes meios de comunicação especializados. Para Meneghini (2009), duas variáveis têm colaborado para a melhoria na qualidade das revistas nacionais: a dedicação dos seus editores e o programa SciELO. ${ }^{6}$

Um anúncio de crescimento dessa magnitude na produção científica brasileira, independente das causas que o geraram, certamente cria uma onda positiva de euforia e isso pode representar, consequentemente, uma maior demanda por publicação de trabalhos em periódicos brasileiros indexados naquela base internacional e também na SciELO. Isso sem falar nas exigências já conhecidas de "produtividade acadêmica" (cf., entre outros, WALTERS, 2006; SILVA JR. \& SGUISSARDI, 2009; SILVA, 2008; CASTRO \& PARENTONI, 2000), nos tão propalados índices de desempenho e nos outros mecanismos de avaliação de periódicos, como o Qualis. $^{7}$

O interesse por indicadores quantitativos gerados pela larga aplicação dos parâmetros da cientometria, ${ }^{8}$ como o fator de impacto, principalmente, o índice de imediatez, o índice de obsolescência e o índice $H$, entre outros, nos últimos quinze anos, tem sido cada vez maior, uma vez que estes representam parte importante das estratégias não só de agências e agentes científicos, mas também de autoridades

\footnotetext{
${ }^{6}$ A Scientific Electronic Library On-Line (SciELO) foi criada em 1997, a partir do desenvolvimento de metodologia específica de armazenamento, disseminação e avaliação de publicações científicas brasileiras em formato eletrônico, produzindo e publicando ainda indicadores estatísticos de uso do sistema e fatores de impacto. Esta biblioteca virtual vem operando regularmente desde junho de 1998, integrando uma grande quantidade de publicações nacionais em sua coleção, com livre acesso ao seu conteúdo: atualmente, são 234 títulos correntes, sendo que, destes, cerca de 90 estão indexados no ISI. O portal de periódicos da Coordenação de Aperfeiçoamento de Pessoal de Nível Superior (CAPES) registra hoje cerca de 24 mil títulos nacionais. Se a produção científica indexada no ISI aumentou para 103 revistas em 2008, basta fazer as contas para encontrar um panorama quantitativo também longe do ideal, não obstante o alvoroço da comunidade científica causado pelo anúncio de crescimento feito pela Thomson-ISI: cerca de 10\% das revistas brasileiras oficialmente registradas na CAPES integram a SciELO e apenas uma pequena amostra, cerca de 1\%, está indexada na Web of Knowledge britânica.

${ }^{7}$ Criado em 1988, O Qualis refere-se a um conjunto de procedimentos de coleta de dados utilizados para estratificar a qualidade da produção intelectual dos programas de pós-graduação stricto sensu (mestrado e doutorado) e para atender as necessidades específicas do sistema de avaliação da CAPES. A classificação de periódicos é feita por áreas de avaliação e atualizada anualmente. As avaliações são feitas trienalmente e os resultados são disponibilizados a partir de uma lista com a classificação dos veículos científicos utilizados pelos programas de pós-graduação para a divulgação da produção intelectual dos corpos docente e discente. As publicações são qualificadas a partir de estratos indicativos, sendo A1 (peso 100), seguidos do A2 (peso 85), B1 (peso 70), B2 (50), B3 (40), B4 (30), B5 (15) e C (peso nulo). Como os demais aferidores de níveis de qualidade da produção científica, o Qualis também tem sido fonte de questionamentos e controvérsias, desde a sua criação, como pode ser visto em Silva (2009), por exemplo.

${ }^{8}$ Price (1969) define cientometria como o estudo quantitativo da atividade científica. Ela surge como um segmento da Sociologia da Ciência, uma vez que se dedica a estudos quantitativos da produção científica. Para isso, utiliza diversos indicadores estatísticos, matemáticos e bibliométricos para analisar a produção científica e tecnológica, a fim de fornecer mensurações e dados específicos para a compreensão da dimensão deste universo científico e dos mecanismos de pesquisa como uma atividade social (BROADUS, 1987).
} 
governamentais para o planejamento e definição de políticas públicas específicas para a área de Ciência, Tecnologia e Inovação (CT\&l).

Outro movimento também vem sendo impulsionado por esta perspectiva voraz de crescimento anunciado em 2009: a corrida pela melhoria da qualidade editorial, formal e de conteúdo, dos periódicos nacionais. Estariam os editores e suas equipes de produção editorial preparados para esta avalanche repentina por publicação, especialmente daquelas revistas com elevado conceito de avaliação e posição consolidada no ranking das publicações nacionais, agora também em franco processo de internacionalização?

Esta breve passagem por alguns conceitos e dimensões importantes da atividade científica, com foco no seu principal meio de comunicação e informação, que são as revistas científicas, tem o objetivo de trazer elementos para refletir sobre o atual papel do editor especializado nesta área, diante de um cenário em constante transformação. Os aspectos anteriormente considerados demonstram a complexidade que envolve este campo da atividade científica, exigindo do editor, como avaliador e mediador do fluxo de comunicação, uma postura de constante atualização e reflexão quanto às práticas e conceitos que envolvem esta atividade. Por isso, é oportuno, neste momento, debater sobre a sua importância neste cenário, sobre suas possibilidades e realidades de formação profissional e intelectual, além de gestor para lidar com a dinâmica da produção científica, com suas diretrizes e exigências de qualidade e busca incessante por visibilidade $\mathrm{e}$, consequentemente, por recursos financeiros tão necessários à continuidade desses meios de comunicação especializados.

As revistas ainda são consideradas como o modo mais rápido e economicamente viável para os cientistas fazerem circular e tornarem visíveis os resultados de seu trabalho. Com o surgimento de novos programas de pós-graduação em nível nacional e a criação de institutos e centros de estudos e pesquisas, a procura crescente por meios eficazes para publicação dos resultados dessa produção de conhecimento tem gerado um nova demanda por veículos especializados de divulgação, feito surgir e desaparecer revistas ao longo dos anos e criado um workflow nunca experimentado na história da comunicação científica.

De que recursos e ferramentas dispõe o editor para lidar com essa nova carga de responsabilidades e desempenhar uma atividade igualmente exigida e em constante processo de atualização e avaliação? Quem é este avaliador e mediador de todo o fluxo de produção editorial acadêmica e científica? De que meios de formação e atualização 
profissionais dispõe para se situar em um mercado em franca expansão e que exige competências e habilidades crescentes?

\section{O EDITOR: ALGUMAS REFLEXÕES}

Muito antes do surgimento das primeiras publicações científicas, é possível verificar o aperfeiçoamento de uma atividade que já existia desde Roma antiga, voltada, ainda de forma artesanal, para a organização, sistematização e difusão do conhecimento: o editor na figura do copista erudita, responsável pela pesquisa, preparação e reprodução caligráfica de textos escolhidos como importantes para o desenvolvimento cultural humano.

Com o advento da tipografia, desenvolvida por Johannes Gutemberg, por volta de 1439, esta atividade começou a deixar para trás a sua característica artesanal, a partir do aperfeiçoamento das técnicas de impressão e reprodução, que tornaram os livros acessíveis a um maior número de pessoas. A nova tecnologia acabou se espalhando por toda a Europa e, mais tarde, para outros continentes, marcando o início de uma nova era para a humanidade.

Usada inicialmente apenas para a impressão e distribuição de livros e folhetos, não demorou muito para a sua aplicação se estender a outras áreas da atividade editorial, como a comunicação científica, abrindo um novo campo para os primeiros editores dessa área, agora em um ambiente tecnicamente favorável à reprodução documental em larga escala.

O editor, responsável pelo gerenciamento de todo o processo de produção editorial de uma revista científica, contudo, ainda carece de ambientes de formação e atualização profissionais, mesmo depois de decorridos vários séculos desde o surgimento dessa atividade. Pode-se mesmo afirmar que são praticamente inexistentes as oportunidades e espaços de formação de editores, tanto no âmbito de graduação como de pós-graduação. Mesmo os cursos universitários de Editoração na área de Comunicação Social, que oferecem um leque de conhecimentos básicos para o exercício profissional no mercado editorial, estão mais voltados às atividades de editoras comerciais. Não há uma formação específica profissional para o editor de revistas científicas, função normalmente ocupada por pesquisadores da área sem a necessária formação técnica para promover ou coordenar processos editoriais como um todo.

Sendo o livro, de um modo geral, e a revista especializada produtos que apresentam diferenças conceituais acentuadas, é acertado falar em uma formação 
específica para o campo da editoração científica. Para atender em parte esta demana, a Associação Brasileira de Editores Científicos (ABEC) vem oferecendo regularmente cursos rápidos que suprem algumas das deficiências encontradas. Criada em 1985, a ABEC, com sede no Rio de Janeiro, tem como finalidade congregar

(...) pessoas físicas e jurídicas com interesse em desenvolver e aprimorar a publicação de periódicos técnico-científicos; aperfeiçoar a comunicação e divulgação de informações; manter o intercâmbio de idéias, o debate de problemas e a defesa dos interesses comuns. (ABEC, 1986, art. 10\%). ${ }^{9}$

Em seguida, em seu artigo 2oㅡ estabelece que, para atingir estas metas, deverá:

(...) a) zelar pelo padrão da forma e conteúdo das publicações técnico-científicas no país; b) promover periodicamente um encontro nacional dos associados; c) manter contato com instituições e sociedades correlatas do país e do exterior; d) divulgar regularmente matérias de interesse editorial técnico-científico; e) promover conferências, seminários e cursos no âmbito de seus objetivos. (art. 2)

Por outro lado, embora a função do editor esteja genericamente vinculada à atividade profissional do jornalista, não existe, no entanto, a especificidade ocupacional para o editor de revistas científicas, exercida, normalmente, por pesquisadores e profissionais de diferentes áreas do conhecimento. De acordo com a Classificação Brasileira de Ocupações (CBO), do Ministério do Trabalho e Emprego (MTE), a função de "Editor" aparece sob o código 2611-20 (referente a "Profissionais do Jornalismo"), desdobrando-se nas seguintes subcategorias: Editor-assistente, Editor de arte, Editor de fotografia, Editor de imagem, Editor de rádio, Editor de web, Editor de área, Editorexecutivo. A seguinte descrição sumária é apresentada:

Recolhem, redigem, registram através de imagens e de sons, interpretam e organizam informações e notícias a serem difundidas, expondo, analisando e comentando os acontecimentos. Fazem seleção, revisão e preparo definitivo das matérias jornalísticas a serem divulgadas em jornais, revistas, televisão, rádio, internet, assessorias de imprensa e quaisquer outros meios de comunicação com o público.

Estariam as revistas científicas incluídas nesta definição, uma vez que o termo "editor científico" englobaria atividades correlatas das áreas de comunicação e ciência? Não necessariamente. Deve-se considerar como editor científico apenas aqueles pesquisadores que, além de suas atividades acadêmicas, desenvolvem outras relacionadas à editoração de revistas científicas de sua área de especialidade, ou nesta categoria poderiam ser incluídos todos aqueles que desenvolvem funções dessa mesma

\footnotetext{
${ }^{9}$ Para conhecer mais sobre a ABEC, acesse a sua página virtual: <http://www.abecbrasil.org.br/>, onde é possível acompanhar os diversos eventos como congressos, reuniões, workshops, entre outras informações relevantes para editores científicos.
} 
natureza, embora apresentem formação em ciências da Comunicação ou da Informação, por exemplo? Certamente, este é um assunto que mereceria ser debatido, a partir das possíveis interpretações para essas prerrogativas legais, em consonância com a necessidade de se estabelecer parâmetros profissionais, competências e habilidades mais precisas para a função de editor científico.

No final das contas, o que parece se configurar com uma necessidade geral para desempenhar as atividades de editor de revista científica é a formação em nível superior, de preferência com pós-graduação, uma sólida formação cultural, que inclui o domínio de pelo menos um idioma a mais que o nativo, conhecimentos prévios sobre o mercado editorial em questão, capacitação para lidar com ferramentas específicas de gerenciamento de publicações, como o Sistema Eletrônico de Editoração de Revistas (SEER), do Instituto Brasileiro de Informação em Ciência e Tecnologia (IBICT), e o Submission (SciELO); finalmente, e não menos importante, podemos citar a dedicação e interesse para desvendar um campo onde o processo de formação profissional depende, basicamente, de uma dinâmica de tentativa, erro e, na melhor das hipóteses, de acerto.

Não se pode esquecer, também, das exigências de saberes específicos - como o uso de programas de edição de texto, editoração eletrônica e de web design, por exemplo - que colocam o editor numa encruzilhada diante da pouca disponibilidade de meios de atualização e especialização e acabam por criar um quadro de responsabilidades que ultrapassam a organização e acompanhamento das etapas de avaliação e publicação. Além do cuidado com meticulosos aspectos formais e de conteúdo, são exigidos dele conhecimentos de planejamento, administração e, ainda, de distribuição e marketing, entre outros. Por ter de percorrer e coordenar praticamente todas as etapas das atividades necessárias, da produção à impressão de uma revista científica, a escassez de recursos e meios de especialização e a sobrecarga de responsabilidades podem contribuir para que o resultado final de seu trabalho apresente deficiências que concorrem para dificultar o alcance dos níveis de excelência que se deseja para estas publicações.

Para efeito ilustrativo dessa atividade tão necessária ao campo da comunicação científica, consultei os expedientes eletrônicos dos 211 títulos correntes disponíveis na SciELO, das diversas áreas que compõem a sua coleção virtual, a fim de detectar as 
nomenclaturas utilizadas para as funções de editor e discutir a importância de suas posições possíveis no organograma das revistas. ${ }^{10}$

Apresento os dados a seguir sem a pretensão de estabelecer qualquer sistematização teórica, tendo em vista a não aplicação de instrumentos precisos, quantitativos ou qualitativos, para estabelecer parâmetros rigorosos de pesquisa considerados válidos. $O$ intuito é de que estas informações, de alguma maneira, possam servir para ilustrar e impulsionar o debate sobre as responsabilidades e as funções do editor, de um modo geral, dentro da dinâmica de editoração das revistas científicas brasileiras. Ressalte-se, ainda, que a inexistência de estudos nesta área para estabelecer uma categorização precisa de cada função de editor (editor-chefe, editor-adjunto, editorassistente, editor-executivo, entre tantas outras, como veremos a seguir) dificulta o estabelecimento de regras precisas para cada caso funcional. De qualquer modo, é a partir da observação do que ocorre na prática editorial de cada publicação científica que poderemos encontrar alguns parâmetros conceituais preliminares.

Em primeiro lugar, com 66 ocorrências nas 211 revistas $(31,28 \%)$, aparece a função de "editor" no topo dos expedientes, sem qualquer especificação funcional complementar, o que pode levar a supor que se trate de atribuições de editor-chefe (ou responsável). A segunda maior ocorrência foi para "editor-associado", com 56 menções (26,54\%). Em seguida, aparece o "editor-assistente" em 33 expedientes, ou seja, 16,64\% das ocorrências. A atribuição de "editor-chefe" foi utilizada em apenas 18 revistas (8,53\%) e a de "editor-executivo" (8,05\%), em 17. A função de "editor científico" aparece em 10 expedientes, ou seja, 4,74\%. Na sequência, temos: "editor de área" (7 ocorrências: $3,32 \%)$; editor-adjunto (6 menções: $2,84 \%)$, "editor-técnico" com 5 menções $(2,37 \%)$ e "editor de seção" com $3(1,42 \%)$.

A partir daí, começam a aparecer os casos mais interessantes nesta miscelânea funcional, alguns merecendo ser comentados à parte: o cargo de "editor-responsável" aparece apenas em dois expedientes (0,95\%), a mesma frequência sendo observada para "editor-gerente", "editor-honorário", "editor de resenhas" e "editor eletrônico". Em

10 Pesquisa feita em 20 de julho de 2010, a partir de consulta ao seguinte endereço eletrônico: <http://www.scielo.br/scielo.php?script=sci_alphabetic\&lng=pt\&nrm=iso>. Foram considerados apenas os 211 títulos correntes, uma vez que 24 periódicos mudaram de título (estando contemplados, portanto, nos 211 pesquisados) e um deles teve sua indexação interrompida em janeiro de 2005, conforme consta no referido sistema. Busquei em cada expediente a ocorrência para a palavra "editor", em forma composta ou não. Optei pela utilização dos termos no singular e no masculino (aos estudiosos de gênero, minhas desculpas), para facilitar a visualização por categoria. Procurei grafálos, ainda, procurando seguir as regras ortográficas vigentes para formação de palavras compostas. Os dados disponíveis nos expedientes das revistas da coleção eletrônica podem ainda não corresponder fielmente aos respectivos expedientes impressos, uma vez que a sua atualização depende, em grande medida, do fornecimento constante de informações por parte dos editores de cada revista, sempre que alguma alteração é promovida. 
seguida, temos ocorrências únicas (0,47\%) para: "editor-coordenador", "editor-prévio", "primeiro-editor", "editor principal", "editor de artigos de revisão", "editor-convidado", "coeditor", "editor-financeiro", "editor de layout”, "coeditor-temático", "editor de criação", "editor de debates", "editor-emérito", "editor de estatística”, "editor-correspondente", "editor junior", "editor para normalização” e, finalmente, "editor-internacional”.

O primeiro movimento que proponho fazer para tentar entender esses dados em seu conjunto é um exercício de recomposição, ou seja, procurar identificar categorias que poderiam melhor se encaixar nas de maior frequência de utilização, que são também as mais encontradas nos periódicos nacionais como um todo:

- Editor científico (10), objeto das reflexões desse trabalho, editor-responsável (2), que aparece geralmente em revistas jornalísticas ou até mesmo de divulgação científica, e editor-coordenador (1) poderiam ser englobados na categoria "editorchefe" (18) - correspondendo agora a 31 ocorrências.

- Como a categoria singular de editor (66) só faz sentido quando não há outros editores listados no expediente (coisa rara em revistas científicas, sempre amplas em colaboradores internos e externos), sendo ainda editor principal (1) que teria mais sentido junto com um secundário - primeiro-editor (1) - também carente de sentido, na falta de um segundo na hierarquia - e editor prévio (1) termos pouco usuais em expedientes de revistas, então, seria mais adequado incluí-los também na categoria "editor-chefe" (31), que somaria 100 ocorrências.

- Editor-convidado (1), editor-correspondente (1) - se no mesmo sentido de internacional - e editor internacional (1) seriam incluídos em "editor-associado" (56): com 59 ocorrências agora.

- Editor de área (7), editor de resenhas (2), editor de artigos de revisão (1), editor de debates (1) e coeditor-temático (1) poderiam se somar a "editor de seção" (3), que resultaria em 15 ocorrências. Todavia, estas categorias parecem ser mais de caráter operacional interno de plataformas de gerenciamento eletrônico de editoração, do que de figuração oficial em expedientes. ${ }^{11}$

\footnotetext{
${ }^{11}$ É importante ressaltar que plataformas de gerenciamento, como o SEER e o Submission, apresentam as funções editoriais previstas especificamente para efeito operacional dos sistemas, não entendendo, portanto, que possam ou devam ser representadas e aplicadas da mesma maneira nos expediente de cada revista. $O$ editor-gerente, nesses sistemas, pode não corresponder ao editor-chefe ou ao executivo no expediente, mas sim ao editor-assistente, por exemplo. A observação cuidadosa dos casos mais comuns em expedientes e organogramas e o bom senso na hora de distribuir tarefas e nomear funções são boas saídas para evitar algumas imprecisões.
} 
- $\quad$ Coeditor (1) e editor junior (1) - que seria o segundo na hierarquia, pois haveria o editor sênior - poderiam se somar a "editor-adjunto" (6), resultando em 8 ocorrências;

- Editor-gerente (2) aproxima-se mais da função de editor-assistente, que passaria a contar 35. Permanece, portanto, inalterada a contagem para editor-executivo (17).

Algumas denominações, pela peculiaridade de sua aplicação, não puderam ser enquadradas nas maiores ocorrências observadas. As duas primeiras parecem ser resultantes de necessidades editoriais e institucionais singulares no momento de atribuir funções estratégicas; outras, consideradas esdrúxulas, podem ser resultantes da inobservância ou desconhecimento das estruturas editoriais mais comuns. Eis os exemplos:

- Editor-honorário (1) é uma denominação de mérito atribuída a pesquisador que, por sua contribuição institucional ou ao campo do conhecimento em que determinada revista científica está inserida, passa a figurar como membro permanente nos créditos editoriais, tal como ocorre com editor emérito (1).

- Editor-técnico (5), denominação que apresenta ocorrência escassa em revistas da área das humanidades, aparecendo, na maioria das vezes, em algumas publicações de ciências exatas e tecnológicas, ainda de forma inadequada quanto ao que parece ser a sua função original. O editor de estatística (1), por exemplo, poderia se adequar bem a esta categoria, no sentido da colaboração de especialista como editor de todo ou parte de artigo científico ou mesmo texto técnico (como de agrimensura, meteorologia, determinadas áreas do Direito, manuais de programas operacionais de informática e computação, entre outras). Ou seja, o "editor-técnico" atuaria em situações muito peculiares, como editor especial, em texto científico ou mesmo publicação técnica. A mesma peculiaridade ocorre com "revisor-técnico", termo muito aplicado em casos de necessidade de verificação se a terminologia de certa área foi preservada, ao se traduzir um documento ou artigo científico); isto é, restringe-se a sua atuação como especialista em determinada área de conhecimento. OBS: Numa revista científica, é preciso cautela para não confundir editor-técnico e revisor-técnico com editores de conteúdo geral ou mesmo revisores de linguagem formal ou de aspectos referentes a normas técnicas (como as da ABNT ou de Vancouver). 
- Editor eletrônico (2), editor de layout (1), editor de criação (1), editor- financeiro (1) e editor para normalização (1) são outros termos encontrados que merecem um esclarecimento quanto a sua utilização na organização das funções editoriais. Quando falamos em editoração eletrônica (desktop publishing), nos referimos à aplicação de técnicas de edição/diagramação de conteúdo com a utilização de equipamentos e programas operacionais próprios para este fim, como Page Maker e In Design. Esta etapa de trabalho nas revistas científicas é feita por um profissional das artes gráficas e visuais, conhecido como editorador ou diagramador, sendo inadequado, portanto, chamá-lo de "editor eletrônico". Os casos do editor de layout e do editor de criação são similares ao de editorador, uma vez que se referem também à função de web design e gerenciador de forma $\mathrm{e}$ conteúdo eletrônicos para a internet, podendo ainda ser chamados de artefinalistas dentro da produção de uma revista científica ou mesmo livro, mas raramente de editores. Já o termo editor de normalização nada mais é do que o revisor de normas técnicas, ou seja, não se trata necessariamente de uma função de editor. Por sua vez, o termo editor-financeiro faria mais sentido numa publicação especializada em economia, administração ou contabilidade, ou seja, ele seria um especialista em finanças, podendo o termo ser aplicado com mais coerência, neste caso, como "editor-técnico"; e como "secretário de finanças", por exemplo, caso seja o responsável por controle financeiro interno. Além do mais, é acertado dizer que "finanças", no sentido de recursos financeiros, não são objeto de "edição", mas de gerenciamento.

Outra situação interessante, mas preocupante do ponto de vista das imprecisões, é a inserção do editor científico em campo específico da equipe de produção editorial (onde figuram, entre outros, revisores, diagramadores e prestadores de serviços gráficos e de impressão, que são também essências à qualidade final), quando se observa que esta função está profundamente relacionada com as especialidades definidas pela política e escopo editoriais da publicação, pertencendo, portanto, a níveis superiores na hierarquia editorial.

Em alguns expedientes pode-se verificar, ainda, a existência de funções de "jornalista-responsável" e "jornalista científico", sendo que este último se aplica mais ao especialista existente em editorias de Ciência \& Tecnologia, em jornais e revistas de divulgação e/ou informação, do que à comunicação científica propriamente dita. Não se pode esquecer que, em revistas científicas, não costuma haver o espaço físico, o setor 
destinado exclusivamente à redação do texto, que existe em veículos jornalísticos. Com raras exceções, em revistas científicas a tendência é o uso de termos como "Comitê Editorial" ou "Comissão Editorial", em vez de "Comitê de Redação" ou "Secretaria de Redação" ou mesmo a função de "redator". Estas publicações dependem da colaboração externa de especialistas, que são os redatores de seus próprios trabalhos, e submete-os à apreciação dos editores das revistas científicas. Os editoriais são o raro exemplo de atividades internas de redação em um periódico dessa natureza.

\section{O EDITOR EM REVISTAS CIENTÍFICAS}

Ressalvadas as diferenças existentes para a função de editor no campo do Jornalismo, cabe aprofundar a discussão para a função do editor particularmente na área de revistas científicas. Embora não se possam ignorar as diferenças por áreas e as necessidades internas das políticas editoriais e institucionais de cada periódico científico, observam-se, ao mesmo tempo, nos expedientes consultados, uma tendência à organização clássica de suas atividades, que aponta para acentuada padronização de seus modos de operação, bem como diversos casos de imprecisão conceitual quanto às formas de distribuição das tarefas operacionais referentes ao editor. Tais fragilidades conceituais podem contribuir, sobremaneira, para uma interpretação e aplicação inadequadas das propostas de organogramas e fluxogramas para revistas científicas.

A partir do modo como as publicações se organizam ou poderiam se organizar internamente, é possível entender a importância estratégica da formação de editores como incremento da qualidade que se deseja para estes meios de comunicação especializada. Com base nisso, buscando alinhar as várias funções listadas a partir dos expedientes disponíveis na SciELO e resumir as funções básicas do editor científico, proponho um segundo exercício, agora de elaboração de organograma funcional, sem qualquer pretensão de caráter prescritivo, mas sim ilustrativo. Embora semelhante ao clássico (vertical), ${ }^{12}$ este não prioriza a representação de relações hierárquicas, mas sim a importância das etapas funcionais (internas e externas) mais comuns de uma revista.

\footnotetext{
12 O organograma é, resumidamente, um modelo representativo das unidades funcionais de uma instituição. Desenvolvido por Daniel McCallum, em meados do século XIX (EUA), veio sendo adotado largamente como modelo organizacional pelos setores administrativos das empresas, ao longo do século XX. Alguns outros tipos mais conhecidos são: o clássico (ou vertical, de caráter meramente hierarquizante); o horizontal, que, embora procure definir as hierarquias, dispõe as funções lateralmente, suavizando essas relações; o radial (ou circular), que serve para representar as interações, a cooperação e o trabalho grupal; o matricial, usado por instituições com estrutura informal, ou seja, que não possuem unidades funcionais bem definidas, mas grupos e rodadas de tarefas geralmente temporárias.
} 
Figura 1: As funções do editor: proposta de organização para revista científica

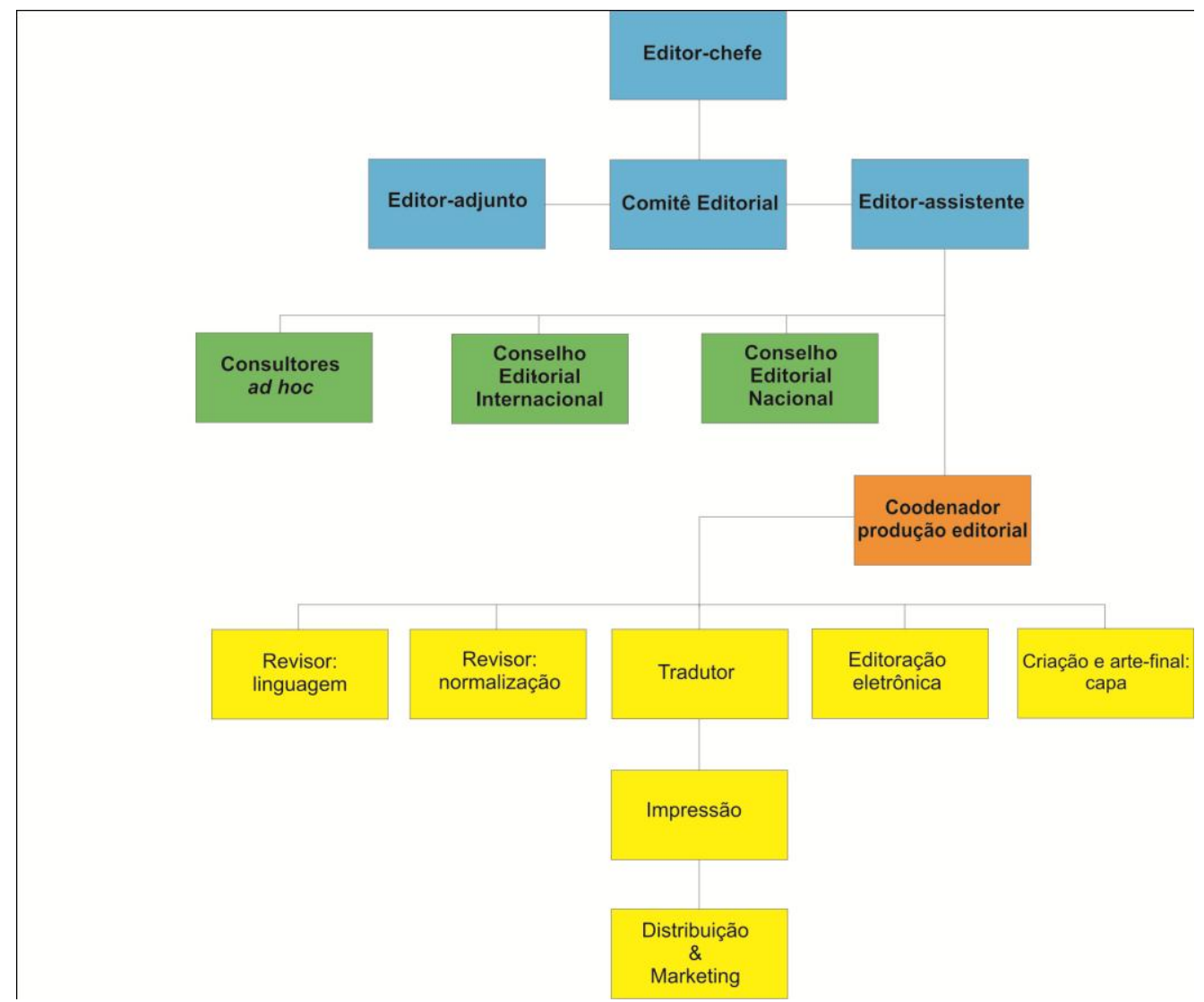

Observa-se que as funções do editor, neste modelo funcional aqui proposto, são desdobradas em diversas categorias e perpassam as principais etapas de produção editorial de uma revista científica: o ordenamento institucional e financeiro, o recebimento/captação das colaborações e recursos, a seleção e avaliação dos textos, o gerenciamento e organização do conteúdo e a produção editorial, entre outros. Esta proposta de estruturação de um corpo editorial é apenas um exercício, como já salientado, para demonstrar uma das muitas formas de se organizar os recursos humanos disponíveis e necessários para uma revista, a partir principalmente das funções do editor. Obviamente, as diferenças e peculiaridades de cada publicação é que vão definir as suas necessidades funcionais e poderão desdobrar as etapas e as tarefas, agregando mais profissionais para a execução da editoração científica como um todo.

Verifica-se no referido organograma a disposição das unidades funcionais a partir de grupos cromáticos, compondo assim um indicatico daquelas etapas de caráter mais interno à gestão da revista, seguidas de etapas de avaliação externa e de produção editorial.

Dentre as ocorrências apresentadas nos expedientes pesquisados, ainda com base na experiência com editoração científica e ensino de disciplinas referentes à formação do 
editor, embora comercial, proponho aqui três funções correlatas (em azul) para a organização de uma revista científica:

1) o editor-chefe - que pode ser o cientista ou o que responde diretamente pelo direcionamento político e institucional da publicação, como meio de disseminação de conhecimento na área em que se insere, e coordena as suas atividades editoriais.

2) o editor-adjunto - que pode ser também executivo, com amplos conhecimentos da estrutura editorial como um todo e, na ausência do primeiro, responsável pelas atividades correlatas. Em geral, o editor executivo possui um nível de informação geral e estrutural do periódico, com amplos conhecimentos administrativos e técnicos. É importante, por exemplo, que ele entenda todas as etapas da editoração, mesmo que não esteja diretamente envolvido em sua execução. É ainda responsável pela gestão dos recursos financeiros e pela observação constante das tendências editoriais e de mercado, tanto como de avaliação e visibilidade editoriais, oferecendo ao editor-chefe e ao comitê editorial informações e parâmetros essenciais para balisar as decisões a serem tomadas;

3) o editor-assistente, por sua vez, é o mediador entre as atividades das esferas de gestão política e financeira da revista e as de avaliação de produção científica, a partir das decisões do comitê editorial, do editor-chefe e do editorajunto ou executivo, como responsáveis imediatos pela qualidade do conteúdo a ser publicado. $O$ editor-assistente preocupa-se com o recebimento, a organização e a sistematização dos processos de seleção e arbitragem de textos em geral, que são a matéria-prima e razão de ser de uma publicação científica. Deve possuir amplos conhecimentos sobre as formas e meios eletrônicos de editoração de conteúdo, que supõe as fases de captação, avaliação e preparação editorial para impressão, além de capacidade de coordenação de equipe editorial.

Em seguida, considerei um núcleo de avaliação externa (verde), composto por conselhos editoriais em três níveis: nacional, internacional e ad hoc (estes acionados em caso de sobrecarga de trabalho dos demais conselhos ou para suprir uma necessidade teórica de arbitragem de artigo, que não encontra especialistas em seu corpo nacional ou internacional).

Depois, estão estruturadas as células funcionais responsáveis pela execução das importantes etapas referentes à produção editorial da revista: o coordenador editorial (em 
laranja), aqui posicionado em nível interno, sendo responsável pela execução do trabalho da equipe de produção (amarelo), que pode ser tanto interna quanto externa: prestadores de serviços terceirizados. Contudo, isso dependerá do aporte de recursos financeiros disponíveis e, ainda, da política institucional em que a publicação está inserida. São muitos os exemplos de revistas que, hoje, têm as etapas finais de sua produção sendo executadas por uma editora universitária (que já possui o seu coordenador, gerente ou produtor editorial), como parte da estratégia institucional de centralizar as suas publicações, assim como há outras que, com exceção da fase de captação, seleção e avaliação de conteúdo, repassam toda a produção final para uma editora comercial ou mesmo empresa de serviços gráficos.

Neste momento, entende-se que os níveis possíveis de qualidade do conteúdo já devem estar assegurados pelos processos de pré-seleção, análise editorial e avaliação por pares. A fase de produção editorial (revisão de linguagem, tradução, criação e arte, diagramação ou editoração eletrônica, entre outras) de uma revista científica caracterizase como uma das últimas e essenciais etapas para se alcançar e manter os padrões de qualidade formal tão exigidos para estes meios de comunicação especializada. A existência de uma equipe de produção formada por profissionais experientes, bem alinhados aos objetivos e orientações editoriais e atualizados é, portanto, fator decisivo para o sucesso e a manutenção de qualidade de qualquer publicação.

\section{CONSIDERAÇÕES FINAIS}

As revistas científicas ocupam, hoje, um lugar central nos modos de organização e troca entre as comunidades científicas e acadêmicas e, também, entre estas e a sociedade. Do florescimento à proliferação, como um meio de comunicação dos resultados dos estudos científicos em diversas áreas do saber, estes veículos têm servido também como importantes instrumentos de mudanças políticas e de alterações na própria estrutura interna dessas comunidades. Hoje, são raros os casos de associação científica ou instituição acadêmica que não edite, concomitante às suas atividades, uma revista impressa ou eletrônica.

Por sua vez, os editores desses veículos, em suas diversas manifestações funcionais, são os avaliadores e mediadores por excelência desse fluxo contínuo entre estas comunidades e seus pares, espalhados ao redor do mundo, agora com a possibilidade de acesso ampliado e até ilimitado pelas redes de conhecimento, que também se estruturaram ao longo das últimas décadas para redefinir meios de controle, 
sistematização, documentação, arquivo e avaliação deste trabalho. As tecnologias de informação e comunicação, por meio das mídias digitais e da internet, são hoje o maior responsável pelas alterações nos modos de operar da comunicação científica, exigindo cada vez mais velocidade, transparência e qualidade de forma e de conteúdo dos fluxos editoriais.

Em face deste panorama, como posicionar o editor diante desta avalanche de exigências e redirecionamentos? Sua importância, como profissional especializado e em busca de constantes meios de formação e atualização, se faz perceber nas diversas fases históricas que o conhecimento científico percorreu. Graças ao seu empenho em manter sempre aberta uma via democrática de divulgação do saber gerado, ele tem ajudado a ampliar também a representatividade da ciência no cenário da comunicação nacional e internacional, reafirmando uma relação de parceria que vem se desenvolvendo e se fortalecendo desde os primórdios da comunicação científica.

É oportuno, neste momento de possíveis mudanças no cenário da comunicação científica, estando as questões de visibilidade, acesso e internacionalização de conteúdos na ordem do dia para definição de estratégias e políticas públicas para a área de Ciência, Tecnologia e Inovação, colocar em debate também a necessidade de redefinir os meios e recursos necessários para a formação e atualização do editor científico. As exigências mercadológicas e de saberes específicos, além de um quadro de responsabilidades que ultrapassam a organização e acompanhamento das etapas de avaliação e publicação, como planejamento, administração e, ainda, de distribuição e marketing, entre outros, têm colocado o editor numa encruzilhada diante da pouca disponibilidade de meios de profissionalização.

Essa sobrecarga de atividades e anseios pode contribuir, também, para que o resultado final de seu trabalho comece a manifestar outras deficiências que concorreriam, no final, para dificultar o alcance dos níveis de excelência que se exige e deseja às publicações científicas. Este é um desafio que precisa ser enfrentado de forma cooperativa, como se espera, de fato, em uma comunidade geradora de conhecimentos.

Não obstante a existência de relações de hierarquia no corpo editorial de uma revista científica, entende-se, por fim, que, além de conhecimento e dedicação às funções e tarefas que cabem a cada um neste processo de editoração científica, é importante que todos se reconheçam e reconheçam o outro, seja ele editor-chefe, editor-adjunto, executivo, assistente, diagramador ou revisor, como partes essenciais no processo 
editorial e, portanto, corresponsáveis pelos resultados que uma revista venha a alcançar no cenário da comunicação científica. Afinal, a qualidade desse meio especializado depende, em grande medida, da dedicação das diversas partes envolvidas em sua elaboração e das relações de cooperação e troca que dela resultam.

\section{REFERÊNCIAS}

BOURDIEU, P. O campo científico. In: ORTIZ, R. (Org.). Pierre Bourdieu; sociologia. São Paulo: Ática, 1983. p. 122-155.

BRASIL. Ministério do Trabalho e Emprego. Classificação Brasileira de Ocupações. Brasília, DF: MTE. Disponível em: <http://www.mtecbo.gov.br/cbosite/pages/informacoesGerais.jsf>. Acesso em: 16 jul. 2010.

BROADUS, R.N. Toward a definition of bibliometrics. Scientometrics, Budapest, v. 12, n. 6, p. 373-379, 1987.

CASTRO, M.C.L.; PARENTONI, R. Viver sob a pressão dos papers? Jornal da Ciência, Brasília, v. 14, n. 435, 2000.

CHARTIER, R. A aventura do livro: do leitor ao navegador. Trad. de Reginaldo de Moraes. São Paulo: Editora da UNESP; Imprensa Oficial do Estado, 1999.

FREITAS, M.H.A. Origens do periodismo científico no Brasil. 2005. 128f. Dissertação (Mestrado em História da Ciência). Pontifícia Universidade Católica de São Paulo. São Paulo.

FREITAS, M.H.A. Considerações acerca dos primeiros periódicos científicos brasileiros. Ciência da Informação, Brasília, DF, v. 35, n. 3, p. 54-66, set.-dez. 2006.

GARFIELD, E. Citation indexes for science: a new dimension in documentation through association of ideas. Science, Washington, DC, v. 122, p. 108-111, 1955.

GARFIELD, E. Journal impact factor: a brief review. Canadian Medical Association Journal, Otawa, v. 161, n. 8, p. 979-980, 1999.

GOIS, A. Produção científica cresce $56 \%$ no Brasil. Folha de S. Paulo [on-line], São Paulo, Ciência, 6 maio 2009.2 Disponível em: <http://www1.folha.uol.com.br/folha/ciencia/ult306u561181.shtml> Acesso em: 6 jul. 2010.

KUHN, T. A estrutura das revoluções científicas. São Paulo: Perspectiva, 1978.

LEMOS, A.A.B. Presente e futuro do periódico científico. Correio Brasiliense, Brasília, DF, Caderno Cultural, p. 3,13 jul. 1968. Disponível em: <http://www.unirio.br/museologia/escolademuseologia/dicasdeleitura.htm>. Acesso em: 16 jul. 2010. 
LÉVY, P. As tecnologias de inteligência: o futuro do pensamento na era da informática. Rio de Janeiro: Editora 34, 1993.

MACHADO, A. O fim do Livro? Estudos Avançados, São Paulo, v. 8, n. 21, p. 201-214, maio-ago. 1994.

MARTIN, H.J.; FEBVRE, L. O aparecimento do livro. São Paulo: HUCITEC; Editora da UNESP, 1992.

MARTINS, A.L. Revistas em revista. Imprensa e práticas culturais em tempos de República, São Paulo (1890-1922). São Paulo: FAPESP; EDUSP; Imprensa Oficial, 2001.

McLUHAN, M. A galáxia de Gutenberg. São Paulo: Nacional, 1972.

MENEGHINI, R. Inusitado aumento da produção científica. Folha de S. Paulo, São Paulo, 12 maio 2009. Disponível em: <http://www.eagora.org.br/arquivo/ inusitado-aumento-daproducao-cientifica/> Acesso em: 9 jul. 2010.

MERTON, R.K. The sociology of science: theoretical and empirical investigations. Chicago: University of Chicago Press, 1973.

PRICE, D.J. The structures of publication in science and technology. In: GRUBER, H.; MARQUIS, D.G. (Org.). Factors in the transfer of technology. Cambridge: MIT Press, 1969. p. 91-104.

RODRIGUES, J.G.; MARINHO, S.M.X. A trajetória do periódico científico na Fundação Oswaldo Cruz: perspectivas da Biblioteca de Ciências Biomédicas. História, Ciência, Saúde Manguinhos, Rio de Janeiro, v. 16, n. 2, p. 523-532, 2009.

SANTAELLA, L. Culturas e artes do pós-humano: da cultura das mídias à cibercultura. São Paulo: Paulus, 2003.

SCHWARTZMAN, S. Um espaço para a ciência: a formação da comunidade científica no Brasil. Brasília, DF: Ministério de Ciência e Tecnologia; Conselho Nacional de Desenvolvimento Científico e Tecnológico; Centro de Estudos Estratégicos, 2001.

SCHWARTZMAN, S. A pesquisa científica e o interesse público. Revista Brasileira de Inovação, Campinas, v. 1, n. 2, p. 362-395, 2002.

SILVA JR., J.R.; SGUISSARDI, V. Trabalho Intensificado nas Federais: pós-graduação e produtivismo acadêmico. São Paulo: Xamã, 2009.

SINDICATO DOS JORNALISTAS DO ESTADO DE SÃO PAULO. Regulamentação da Profissão de Jornalista. Decreto n. 83.284, de 13 de março de 1.979. Dá nova regulamentação ao Decreto-Lei n. 972, de 17 de outubro de 1969, que dispõe sobre o exercício da profissão de jornalista, em decorrência das alterações introduzidas pela Lei n. 6.612, de 7 de dezembro de 1978. 
SILVA, A.O. Somos todos delinquentes acadêmicos? Espaço Acadêmico, Maringá, v. 8, n. 88, set. 2008. Disponível em: <http://www.espacoacademico. com.br/088/88ozai.htm>. Acesso em: 13 jul. 2010.

SILVA, A.O. A sua revista tem Qualis? Mediações, Londrina, v. 14, n. 1, p. 117-124, jan.jun. 2009.

SMITH, R. Commentary: The power of the unrelenting impact factor - Is it a force for good or harm? International Journal of Epidemiology, Oxford, v. 35, n. 5, p. 1129-1130, 2006.

STUMPF, I.R.C. Passado e futuro das revistas científicas. Ciência da Informação, Brasília, DF, v. 25, n. 3, p. 383-386, 1996. Disponível em: <revista.ibict.br/index.php/ciinf/article/download/463/422>. Acesso em: 12 jul. 2010.

TARGINO, M.G.; GARCIA, J.C.R. Ciência brasileira na base de dados do Institute for Scientific Information (ISI). Ciência da Informação, Brasília, DF, v. 29, n. 1, p. 103-117, jan.- apr. 2000.

VESSURI, H.M.C. La academia va al mercado: relaciones de científicos académicos con clientes externos. Caracas: Fondo Editorial FINTEC; Monte Ávila, 1995.

WATERS, L. Inimigos da esperança: publicar, perecer e o eclipse da erudição. São Paulo: Editora da UNESP, 2006.

\section{Title}

The editor of scientific journals: challengs of practice and training

\section{Abstract}

This article reflects on the responsibilities and function of scientific journals' editors who face a new editorial dynamic, prompted by the current demands of academic productivity and by a better indexing. It discusses the importance of the editors' permanent training in order to accomplish the quality guidelines and requirements of these journals as well as the resources and tools available to assist their editorial activities. It states that since the rise of the pioneers journals in the middle of the $17^{\mathrm{TM}}$ Century until the current exponential arising of new titles, the journals were reasserted as a quick and economically feasible way to circulate and enhance scientific studies' visibility, leading to a workflow never experienced before in the history of the scientific communication.

\section{Keywords}

Scientific communication. Scientific journals. Editor training. Editorial responsability. Editorial quality.

\section{Título}

El editor de revista científica: desafios de la práctica y formación 


\section{Resumen}

Este artículo algunas reflexiones sobre las responsabilidades y funciones del editor de publicaciones científicas ante una nueva dinámica de editoración, impulsada por las demandas actuales de la productividad académica y la búsqueda de indicadores de desempeño satisfactorios de las revistas científicas. Se discute la importancia de su formación y reciclaje para hacer frente a las directrices y requisitos de calidad y visibilidad de estos vehículos. Cuestiona sobre los recursos y herramientas disponibles para el editor desarrollar una actividad que requiere un constante proceso de actualización y de evaluación. Constata que desde el inicio de las publicaciones consideradas pioneras, en la mitad del siglo XVII, hasta el actual aumento exponencial de los nuevos títulos, estas revistas se afirman como la forma más rápida y más económica para los científicos publicar y hacer visibles los resultados de sus estudios, creando un flujo de trabajo que nunca había experimentado en la historia de la comunicación científica.

\section{Palabras Clave}

Comunicación científica. Revista científica. Formación del editor. Responsabilidad editorial. Qualidad editorial.

Recebido em: 11.08.2010

Aceito em: 15.09.2010 